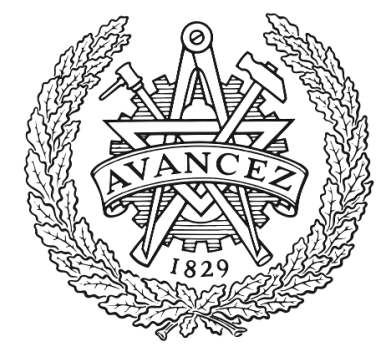

\title{
CHALMERS
}

UNIVERSITY OF TECHNOLOGY

\section{Interplay between CO Disproportionation and Oxidation: On the Origin of the CO Reaction Onset on Atomic Layer Deposition-Grown Pt/ZrO2Model}

Downloaded from: https://research.chalmers.se, 2023-04-26 14:03 UTC

Citation for the original published paper (version of record):

Pramhaas, V., Roiaz, M., Bosio, N. et al (2021). Interplay between CO Disproportionation and Oxidation: On the Origin of the CO Reaction Onset on Atomic Layer Deposition-Grown Pt/ZrO2Model Catalysts. ACS Catalysis, 11(1): 208-214. http://dx.doi.org/10.1021/acscatal.0c03974

N.B. When citing this work, cite the original published paper. 


\title{
Interplay between CO Disproportionation and Oxidation: On the Origin of the CO Reaction Onset on Atomic Layer Deposition-Grown $\mathrm{Pt} / \mathrm{ZrO}_{2}$ Model Catalysts
}

\author{
Verena Pramhaas, Matteo Roiaz, Noemi Bosio, Manuel Corva, Christoph Rameshan, Erik Vesselli, \\ Henrik Grönbeck, and Günther Rupprechter*
}

Cite This: ACS Catal. 2021, 11, 208-214

Read Online

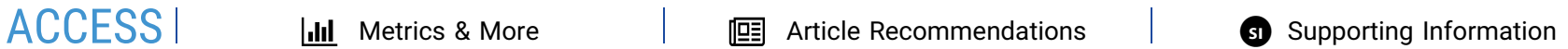

ABSTRACT: $\mathrm{Pt} / \mathrm{ZrO}_{2}$ model catalysts were prepared by atomic layer deposition (ALD) and examined at mbar pressure by operando sum frequency generation (SFG) spectroscopy and near-ambient pressure X-ray photoelectron spectroscopy (NAP-XPS) combined with differentially pumped mass spectrometry (MS). ALD enables creating model systems ranging from $\mathrm{Pt}$ nanoparticles to bulk-like thin films. Polarization-dependent SFG of CO adsorption reveals both the adsorption configuration and the Pt particle morphology. By combining experimental data with $a b$ initio density functional theory (DFT) calculations, we show that the CO reaction onset is determined by a delicate balance between $\mathrm{CO}$ disproportionation

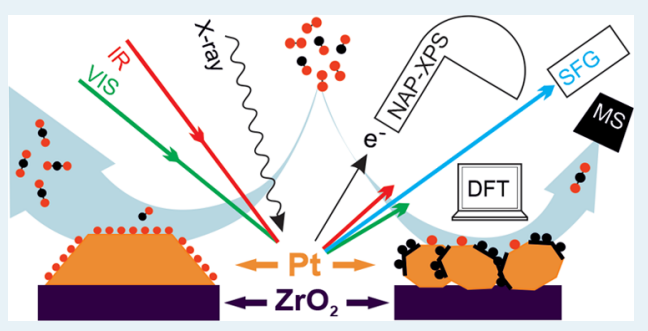
(Boudouard reaction) and oxidation. CO disproportionation occurs on low-coordinated Pt sites, but only at high CO coverages and when the remaining $\mathrm{C}$ atom is stabilized by a favorable coordination. Thus, under the current conditions, initial $\mathrm{CO}$ oxidation is found to be strongly influenced by the removal of carbon deposits formed through disproportionation mechanisms rather than being determined by the $\mathrm{CO}$ and oxygen inherent activity. Accordingly, at variance with the general expectation, rough Pt nanoparticles are seemingly less active than smoother Pt films. The applied approach enables bridging both the "materials and pressure gaps".

KEYWORDS: Pt nanoparticles, catalysis, in situ spectroscopy, operando, SFG, NAP-XPS, DFT

$\mathrm{T}$ he adsorption and catalytic oxidation of $\mathrm{CO}$ on $\mathrm{Pt}$ are among the most frequently examined surface processes due to their environmental and industrial relevance. Pt exhibits superior catalytic properties for various applications, such as (preferential) CO oxidation for emission control or cleaning of hydrogen streams for fuel cells. ${ }^{1-5}$ Despite efforts to replace expensive Pt by cheaper materials, its activity can typically not be matched. Thus, the focus is rather on reducing the $\mathrm{Pt}$ amount, e.g., by using $\mathrm{Pt}$ atoms, clusters, and small nanoparticles $^{6-13}$ (or alloys and core-shell structures ${ }^{14,15}$ ) on suitable support materials. It is, however, still challenging to obtain detailed knowledge about increasingly smaller nanoparticles, especially about their inherent activity and metal/ support interaction. ${ }^{16-21}$

In recent years, significant advances have been made in model catalysis, enabling surface characterization at (near) atmospheric pressure, overcoming the "pressure gap", ${ }^{22-31}$ but bridging the "materials gap" is evenly important. Previous single-crystal studies have provided fundamental insight, but they cannot fully mimic nanoparticles ${ }^{25,32,33}$ (with support effects being apparently inaccessible), which is why more realistic model systems are required, such as oxide-supported nanoparticles/islands ${ }^{11,16,25,34}$ or inverse systems. ${ }^{35-37}$

In this contribution, we present $\mathrm{Pt} / \mathrm{ZrO}_{2}$ model catalysts prepared by atomic layer deposition (ALD) that were examined at mbar pressures by operando sum frequency generation (SFG) spectroscopy and near-ambient pressure Xray photoelectron spectroscopy (NAP-XPS), with simultaneous mass spectrometry (MS) product analysis, and complemented by density functional theory (DFT) calculations.

ALD has been widely used in industrial manufacturing, ${ }^{38,39}$ especially for dielectrics and microelectronics, and is receiving increasing attention for (upscalable) catalyst preparation. ${ }^{40}$ The current model catalysts consist of a zirconia film, ALDgrown (400 cycles) on a Si (100) wafer, and Pt deposits prepared by different numbers of ALD cycles (10-250; see transmission electron microscopy (TEM) images in Figure 1a and Figure S3). Whereas the zirconia ALD generated a uniform $42 \mathrm{~nm}$-thick oxide support, using a few $(10,50) \mathrm{Pt}$ cycles produced small Pt particles up to $8 \mathrm{~nm}$ in size (Figure la, right panel). Upon applying 125 or 250 deposition cycles, the $\mathrm{Pt}$ particles coalesced into islands, finally forming a homogeneous $\mathrm{Pt}$ film of uniform $\sim 10 \mathrm{~nm}$ thickness (Figure 1a,

Received: September 10, 2020

Revised: November 4, 2020

Published: December 17, 2020 

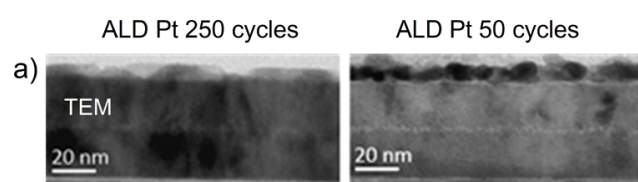

b)
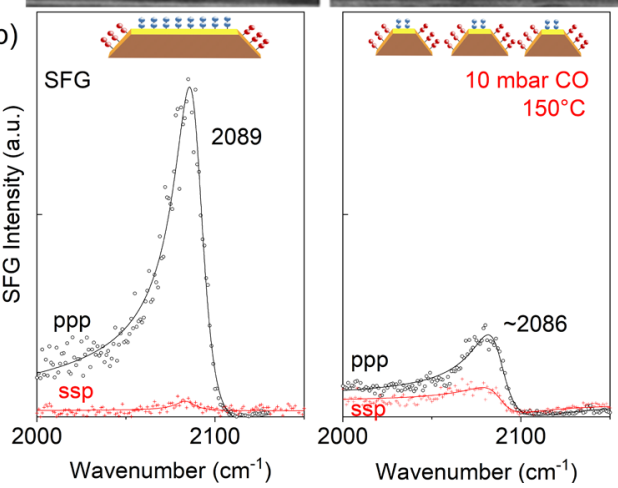

Figure 1. (a) Cross-sectional TEM micrographs of 250 cycle and 50 cycle Pt films. The 250 cycle film consists of large uniform and planar islands ( $\sim 10 \mathrm{~nm}$ in thickness), whereas the 50 cycle film is made up of individual Pt particles (size of about $8 \mathrm{~nm}$ ). (b) SFG spectra in two different polarization combinations (ppp and ssp) of adsorbed CO $\left(10 \mathrm{mbar}\right.$ at $\left.150{ }^{\circ} \mathrm{C}\right)$; the surface morphology of islands/particles (see models) can be assessed by comparing the ppp to ssp intensity (ppp (ssp) has a higher intensity if the $\mathrm{C}=\mathrm{O}$ bond is parallel (tilted) to the macroscopic surface normal).

left panel). These nucleation and growth processes ${ }^{41}$ allow for the preparation of different well-defined $\mathrm{Pt} / \mathrm{ZrO}_{2}$ model catalysts ranging from isolated $\mathrm{Pt}$ nanoparticles to bulk-like thin films. Herein, the 50 and 250 cycle samples are the most informative ones (other samples are described in the Supporting Information). The ALD approach to catalyst synthesis is not new, ${ }^{42,43}$ but the combination with operando surface spectroscopy (SFG and NAP-XPS carried out in highpressure cells with simultaneous MS gas-phase analysis) and DFT calculations provides a complementary picture.

The standard cleaning used for single crystals in ultrahigh vacuum (UHV), i.e., sputtering/annealing, could not be applied as it would have destroyed the ALD samples. Inspired by the (re-)activation of technological catalysts, all samples were thus cleaned from carbonaceous residues by heating in 10 mbar $\mathrm{O}_{2}$ to $400{ }^{\circ} \mathrm{C}$ and in $20 \mathrm{mbar} \mathrm{CO} / \mathrm{O}_{2}(1: 1)$ to $300{ }^{\circ} \mathrm{C}$.

The $\mathrm{Pt}$ morphology was then addressed by polarizationdependent SFG of CO adsorption (10 mbar CO at $150{ }^{\circ} \mathrm{C}$; Figure $1 \mathrm{~b}$; see the Supporting Information for SFG theory and fit values). The spectra show the on-top $\mathrm{CO}$ resonance region, as no other binding geometries were observed. Two polarization combinations were employed: ppp (has its maximum intensity for $\mathrm{C}=\mathrm{O}$ bonds parallel to the macroscopic surface normal; black in Figure $1 \mathrm{~b}$ ) and ssp (has its maximum intensity for $\mathrm{C}=\mathrm{O}$ bonds inclined with respect to the macroscopic surface normal, i.e., around $30-40^{\circ}$ depending on molecular polarizability; red in Figure $1 \mathrm{~b}){ }^{44,45}$ Due to the angular dependence, the resulting intensity ratio $I_{\mathrm{ppp}} / I_{\mathrm{spp}}$ for $\mathrm{CO}$ is expected to decrease with increasing bond inclination of the molecules. ${ }^{46,47}$ Because the Pt film of the 250 cycle sample consisted of planar islands with a uniform height of about 10 $\mathrm{nm}$, adsorbed $\mathrm{CO}$ was mostly perpendicular to the $\mathrm{ZrO}_{2} /$ $\mathrm{Si}(100)$ surface so that the $\mathrm{CO}$ peak intensity was high in ppp and very low in ssp (ratio of 17.4). In light of our previous study of $\mathrm{CO} / \mathrm{Pt}(111),{ }^{47}$ assuming an identical optical interface model, this would correspond to an average CO tilt angle of $\sim 5^{\circ}$ (relative to the macroscopic surface normal), although this value is just meant to show a trend. In contrast, the 50 ALD cycle Pt film consisted of small particles (about $8 \mathrm{~nm}$ ) with multiple facets, many of which are no longer parallel to the substrate. On these inclined facets, $\mathrm{CO}$ still adsorbs

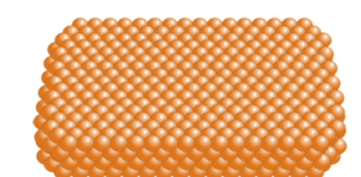

$\mathrm{Pt}(111)$ smooth

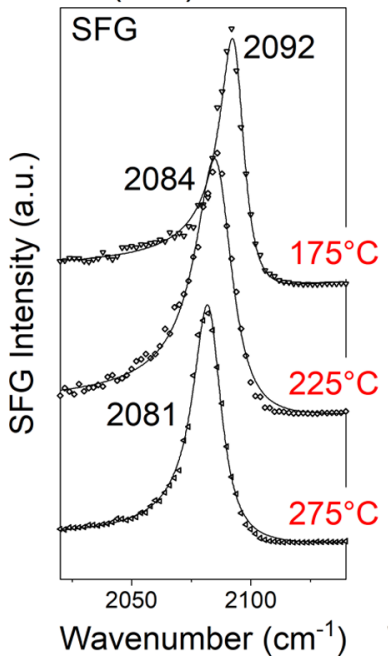

Wavenumber $\left(\mathrm{cm}^{-1}\right)$

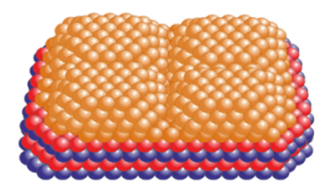

ALD Pt 250 cycles

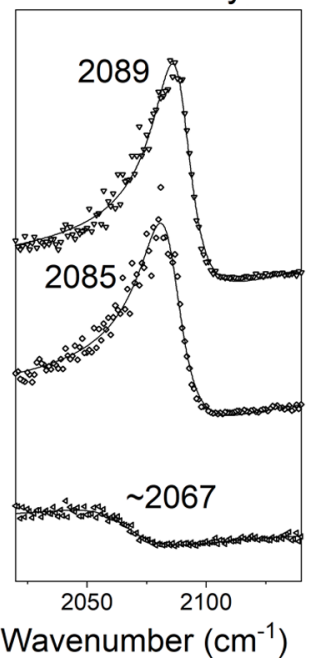

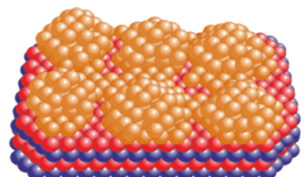

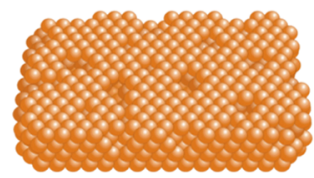

ALD Pt 50 cycles

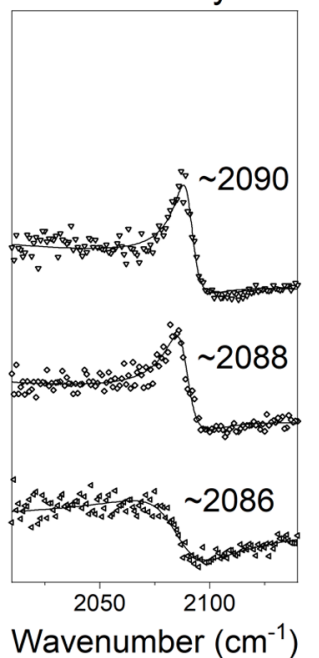

$\operatorname{Pt}(111)$ sputtered

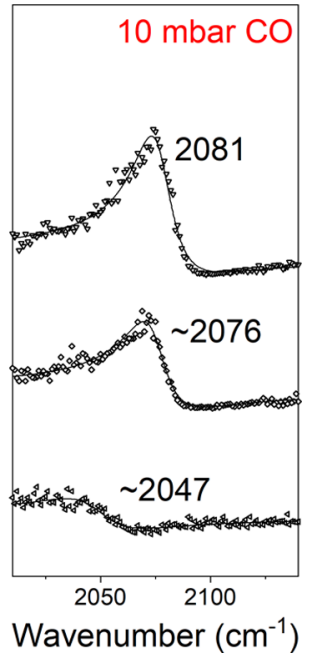

Figure 2. SFG spectra (ppp polarization) displaying on-top CO on different Pt surfaces, acquired in 10 mbar CO at the indicated temperatures. The surface roughness increases from left to right, as indicated by the decreasing intensity and redshift of resonance positions. The indicated values were obtained from data fits (solid lines). For rough surfaces, spectra at $275{ }^{\circ} \mathrm{C}$ showed a diminishing on-top CO, which was irreversible upon cooldown (Figure S10). This cannot be explained by a decrease in CO coverage, as for $\mathrm{Pt}(111)$, the spectrum remained almost unchanged. 
perpendicularly, but the $\mathrm{CO}$ bonds are inclined with respect to the macroscopic surface normal. Accordingly, the SFG intensity is lower in ppp, resulting in a much lower $I_{\mathrm{ppp}} / I_{\mathrm{ssp}}$ ratio of 2.3. Following the same assumptions as above, the average $\mathrm{CO}$ tilt angle would be $\sim 40^{\circ}$ (note that this again is just to show the trend). This rough estimate agrees with the facet inclination and ratio from TEM images.

Apart from the intensity, the peak position and peak symmetry/asymmetry are noteworthy. The peak position depends on the coordination of the $\mathrm{Pt}$ adsorption site and the $\mathrm{CO}$ surface coverage (inducing chemical and dipoledipole interactions). ${ }^{27,48,49}$ As the coverage should be (nearly) the same under identical pressure and temperature conditions, the $3 \mathrm{~cm}^{-1}$ difference points to slightly rougher surfaces for the nanoparticle sample. The (a)symmetry of an SFG signal depends on the amplitudes $A_{\mathrm{r}}$ or $A_{\mathrm{nr}}$ and phase difference $\phi$ between resonant (adsorbed $\mathrm{CO}$ ) and nonresonant signal contributions $^{50-52}$ (see the Supporting Information). The nonresonant background $A_{\mathrm{nr}}$ may originate from Pt surface defects (changing the electron localization at the surface) and electronic contributions of the $\mathrm{ZrO}_{2} / \mathrm{Si}(100)$ substrate. Comparing the spectra of the 250 and 50 cycle samples, the intensities of the resonant and nonresonant contributions are much more similar in the case of the particulate film (smaller particle size, more defects, and more metal/oxide interface), while the resonance phase relative to the nonresonant background, as obtained by means of the quantitative deconvolution of the data, is found to be similar for both $\mathrm{CO}-\mathrm{Pt}$ systems. This leads to a more asymmetric line shape for the 50 cycle $\mathrm{Pt}$, directly reflecting its surface morphology.

In order to further characterize the ALD-prepared model catalysts, they were compared to Pt single crystals at different temperatures. Figure 2 shows the SFG ppp spectra of smooth (UHV annealed to $800{ }^{\circ} \mathrm{C}$ ) $\mathrm{Pt}(111), 250$ and 50 ALD cycle $\mathrm{Pt} / \mathrm{ZrO}_{2}$, and sputtered $\mathrm{Pt}(111)$ in $10 \mathrm{mbar}$ CO. Respective fitting values are given in the Supporting Information (our system has a spectral accuracy of $2 \mathrm{~cm}^{-1}$ ). At $175{ }^{\circ} \mathrm{C}$, the characteristic on-top $\mathrm{CO}$ on $\mathrm{Pt}(111)$ was observed at 2092 $\mathrm{cm}^{-1}$, matching the saturation coverage. ${ }^{49,53}$ The 250 cycle sample exhibited a continuous Pt surface (Figure 1 and Figures S2 and S3), but was still rougher than the annealed $\mathrm{Pt}(111)$, as indicated by the redshifted wavenumber $\left(2089 \mathrm{~cm}^{-1}\right)$ and increased peak asymmetry. Adsorbed $\mathrm{CO}$ on the $50 \mathrm{cycle} \mathrm{Pt} /$ $\mathrm{ZrO}_{2}$ sample, consisting of $8 \mathrm{~nm}$ (connected) particles, exhibited a similar wavenumber, indicating identical coordination, but lower intensity and higher asymmetry due to the inclined facets. The higher number of low-coordinated (step/ kink) sites ${ }^{54,55}$ on the ALD samples was confirmed by comparison with the CO spectra of sputtered $\mathrm{Pt}(111)$ (2081 $\mathrm{cm}^{-1}$ ) and $\mathrm{Pt}(110)\left(2075 \mathrm{~cm}^{-1}\right)$ (Figure S9), showing even lower wavenumbers. ${ }^{53,56}$ Apparently, the ALD Pt catalysts exhibit roughness intermediate between the annealed and sputtered $\mathrm{Pt}(111)$.

Now, turning to the $\mathrm{CO}$ adsorption at higher temperatures $\left(225 / 275{ }^{\circ} \mathrm{C}\right)$, the decreased $\mathrm{CO}$ coverage induced a redshift. ${ }^{24,48,49,53}$ For $\mathrm{Pt}(111)$, the on-top CO signal redshifted, but the intensity was similar to that at $175^{\circ} \mathrm{C}$. Analogously, the CO signals of the ALD samples and sputtered $\operatorname{Pt}(111)$ exhibited small redshifts at $225{ }^{\circ} \mathrm{C}$ (and a minor intensity loss). However, at $275{ }^{\circ} \mathrm{C}$, the rougher surfaces showed a pronounced intensity loss, peak shift, and phase alteration. Previously, a similar observation on polycrystalline $\mathrm{Pt}$ foil ${ }^{57}$ was explained by $\mathrm{CO}$ desorption, but $\mathrm{CO}$ is more strongly bonded to steps/defects than terraces. ${ }^{58,59}$ Furthermore, the spectral changes were irreversible upon cooldown in CO (see Figure S10) and $\phi$ changed significantly, ruling out simple adsorption/desorption and rather suggesting a permanent modification/blocking of the adsorption sites. It has been reported that stepped $\mathrm{Pt}$ surfaces or small $\mathrm{Pt}$ particles/clusters may cause $\mathrm{CO}$ dissociation, forming a carbon overlayer, ${ }^{60}$ in line with the current observation. Indeed, the $\mathrm{CO}$ spectrum of the 250 cycle Pt at $10 \mathrm{mbar} / 225^{\circ} \mathrm{C}$ agrees quite well with the reported values of $\mathrm{Pt}(557)$ at $30 \mathrm{mbar} / 250{ }^{\circ} \mathrm{C}$, which showed $\mathrm{CO}$ dissociation at $275{ }^{\circ} \mathrm{C}$. The dissociation hypothesis is supported by the fact that adding $\mathrm{O}_{2}$ to $\mathrm{CO}$ and heating reversed the spectral change by reoxidizing carbon to $\mathrm{CO}_{2}$ (Figure S11). Nevertheless, CO dissociation on Pt has been controversially discussed for a long time.

This motivated the DFT calculations of CO dissociation on smooth and rough Pt surfaces (Figure 3). CO dissociation on
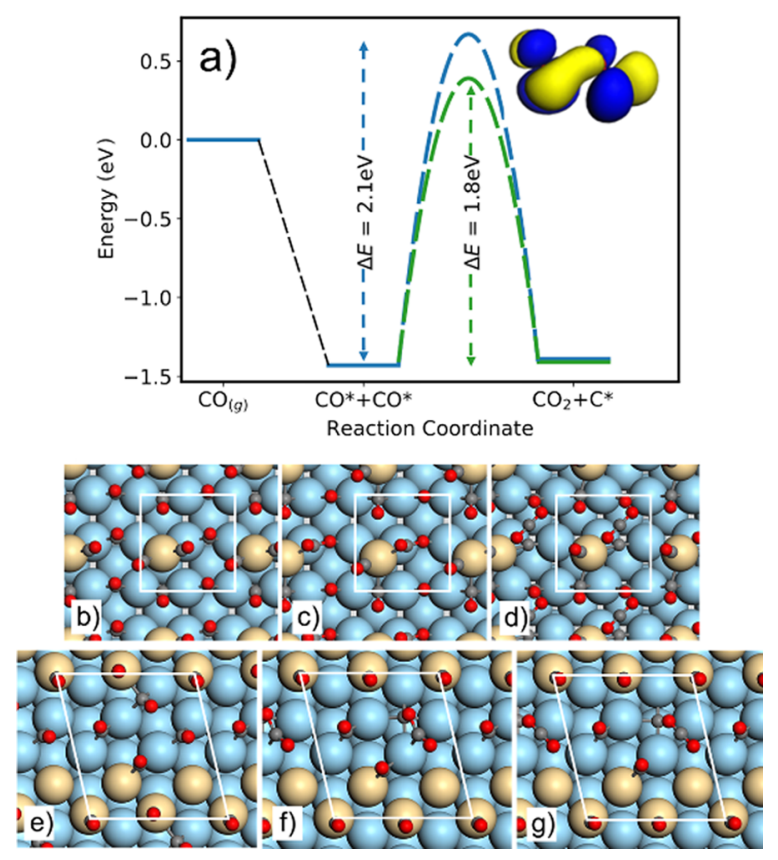

Figure 3. (a) Potential energy diagram for $\mathrm{CO}$ disproportionation over an adatom on $\mathrm{Pt}(100)$ (green) and $\mathrm{Pt}(410)$ (blue). The dissociation is evaluated at the $\mathrm{CO}$ coverage given by a thermodynamic analysis, and the zero level is the saturation coverage minus one $\mathrm{CO}$ molecule and one $\mathrm{CO}$ molecule in the gas phase. The inset shows the HOMO orbital for $(\mathrm{CO}-\mathrm{CO})^{2-}$. Panels $(\mathrm{b})-(\mathrm{d})$ and (e) $-(\mathrm{g})$ show the initial, transition, and final states for dissociation at an adatom on $\mathrm{Pt}(100)$ and $\mathrm{Pt}(410)$, respectively. Atomic color code: $\mathrm{C}$ (dark gray), O (red), Pt adatom or top layer (beige), and Pt (light blue).

$\mathrm{Pt}(111)$ and $\mathrm{Pt}(211)$ is strongly endothermic and barriers $>3$ $\mathrm{eV}$ have been reported in the low coverage limit, ${ }^{61}$ making this process improbable. For a more facile dissociation, the adsorbed state of $\mathrm{CO}$ should be destabilized, whereas the final state needs to be stabilized. A destabilization of the adsorbed state is achieved by increasing the coverage (gas pressure), whereas the final state is stabilized by $\mathrm{CO}_{2}$ formation. In particular, direct $\mathrm{CO}_{2}$ formation according to the Boudouard reaction $\left(\mathrm{CO}^{*}+\mathrm{CO}^{*} \rightarrow \mathrm{CO}_{2}+\mathrm{C}^{*}\right)$ hinders the backward $\mathrm{C}-\mathrm{O}$ association reaction. Similar contributions (local coverage and final state) to favoring the Boudouard reaction have been reported for $\mathrm{PtSn}^{61}$ and $\mathrm{Cu}^{62,63}$ For 
efficient $\mathrm{CO}-\mathrm{CO}$ coupling and reaction, the $\mathrm{C}$ weight of the $2 \pi^{*}$ orbital on one reacting molecule should overlap with the $\mathrm{O}$ weight on the other molecule. This may be accomplished on stepped and kinked surfaces, so we considered two model structures: a Pt adatom coordinated with two $\mathrm{CO}$ molecules on $\operatorname{Pt}(100)$ and $\operatorname{Pt}(410)$. The barriers were evaluated at coverages obtained from a thermodynamic analysis (Figures S14 and S15). The barriers for the reactions are 1.8 and $2.1 \mathrm{eV}$ for dissociation at the adatom and $\mathrm{Pt}(410)$, respectively. For the reaction at the adatom (Figure $3 b-d$ ), one of the $\mathrm{CO}$ molecules on the $\mathrm{Pt}$ adatom is reacting with a $\mathrm{CO}$ on the (100) facet. The transition state is a bent $\mathrm{O}-\mathrm{C}-\mathrm{O}$ structure (Figure 3c), whereas the final state (Figure 3d) is gas-phase $\mathrm{CO}_{2}$ and the remaining carbon atom is in a highly coordinated position. A fourfold coordinated $\mathrm{C}$ on $\mathrm{Pt}(100)$ is (per carbon atom) as stable as graphite, thus stabilizing the final state. ${ }^{64}$ The reaction path on $\mathrm{Pt}(410)$ is different as both reacting $\mathrm{CO}$ molecules are below the step (Figure $3 \mathrm{e}-\mathrm{g}$ ). The $2 \pi^{*}-2 \pi^{*}$ match is, in this case, enabled by an initial bending of the $\mathrm{CO}$ close to the step, and the final state again has a fourfold coordinated $\mathrm{C}$ atom. Accordingly, on the rougher Pt surfaces, $\mathrm{CO}$ dissociation is facilitated by a barrier that is lower than 1 $\mathrm{eV}$ as compared to the smooth surfaces.

Turning to $\mathrm{CO}$ oxidation on the $\mathrm{Pt} / \mathrm{ZrO}_{2}$ model catalysts, Figure $4 \mathrm{a}, \mathrm{b}$ shows the SFG ppp spectra acquired in a reaction mixture of $10 \mathrm{mbar} \mathrm{CO}$ and $20 \mathrm{mbar}_{2}$ from 150 to $500{ }^{\circ} \mathrm{C}$. At $150{ }^{\circ} \mathrm{C}$, the $\mathrm{Pt}$ particles were on-top $\mathrm{CO}$-covered (poisoned) and thus inactive, with $2091 \mathrm{~cm}^{-1}$ indicating high-coordination sites for the 250 cycle sample. The 50 cycle sample showed a $10 \mathrm{~cm}^{-1}$ redshift, indicating lower coordination/higher roughness, with lower intensity and more asymmetry, due to the nanoparticle morphology. Upon temperature increase, the peak of adsorbed $\mathrm{CO}$ decreased and redshifted (due to decreasing CO coverage) and finally disappeared when the $\mathrm{Pt}$ surfaces were fully oxygen-covered and thus active: at $400{ }^{\circ} \mathrm{C}$ for the $\mathrm{Pt}$ thin film, but at $450{ }^{\circ} \mathrm{C}$ for the $\mathrm{Pt}$ nanoparticles. The temperature-dependent shifts were 2091-2080 $\mathrm{cm}^{-1}$ for the smoother Pt film and 2081$2074 \mathrm{~cm}^{-1}$ for the rougher $\mathrm{Pt}$ nanoparticles, the latter wavenumbers indicating stronger bonding on the rougher surfaces. The ignition temperatures were corroborated by the simultaneously acquired $\mathrm{CO}_{2}-\mathrm{MS}$ traces in Figure $4 \mathrm{c}, \mathrm{d}$ and are in accordance with values reported in the literature ${ }^{31,65}$ (note that MS measurements without simultaneous SFG, "laser-off", ruled out any laser-induced effects; Figure S16). As long as adsorbed $\mathrm{CO}$ is present, the oxidation reaction is largely inhibited, as the Pt surface can only be in a single stable state, either CO-poisoned (inactive) or O-covered (active). ${ }^{66}$ Accordingly, both SFG and MS indicated that about $50{ }^{\circ} \mathrm{C}$ higher temperature was required for ignition on the rougher (50 cycle) Pt nanoparticles. This is unexpected, because rougher Pt surfaces are generally considered to be more active in $\mathrm{CO}$ oxidation, ${ }^{9,66}$ as their low-coordinated sites (steps, kinks, and edges) bind both oxygen and $\mathrm{CO}$ stronger than terraces. The $\mathrm{O}$-covered active state can be more easily established on rougher surfaces (indicated by the lower ignition temperature and higher $\mathrm{CO}$ tolerance) despite the higher $\mathrm{CO}$ oxidation barriers ${ }^{67}$ (according to the BrønstedEvans-Polanyi relation ${ }^{68}$ ). However, in the current case, the inherent activity is not the only important factor, as shown in the following.

To further examine the reaction onset, NAP-XPS was applied as the second operando technique (which again rules
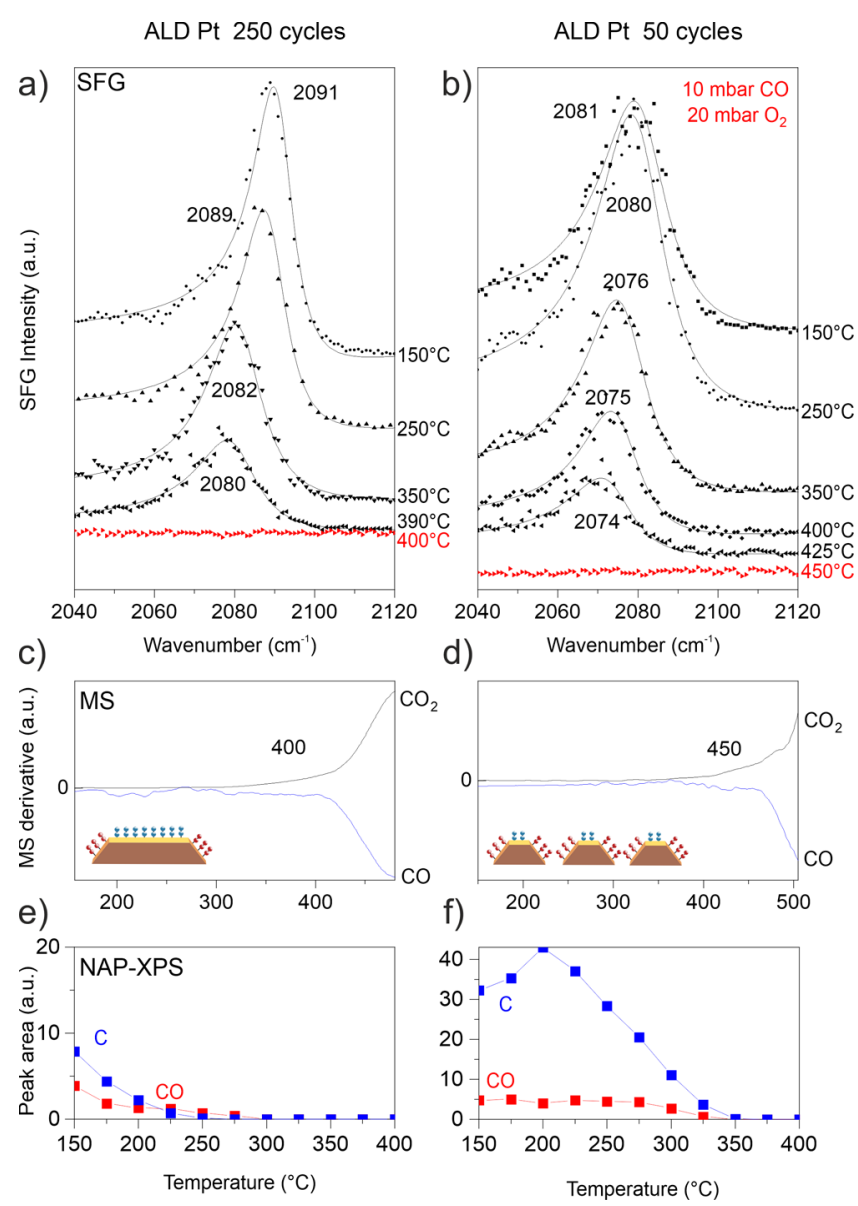

Figure 4. (a, b) SFG spectra (ppp polarization) acquired in $10 \mathrm{mbar}$ $\mathrm{CO}+20 \mathrm{mbar}_{2}$ (batch mode) for the 250 and 50 cycle ALD Pt samples. The spectra redshift at higher temperatures due to reduced $\mathrm{CO}$ coverage until the surfaces fully switch to oxygen coverage. (c, d) Derivatives of the mass spectrometry data of $\mathrm{CO}$ and $\mathrm{CO}_{2}$. For the rougher 50 cycle film, both the disappearance of $\mathrm{CO}$ in SFG and the onset of $\mathrm{CO}_{2}$ production are shifted to higher temperature. (e, f) Temperature-dependent evolution of adsorbed $\mathrm{CO}$ and carbon deduced from $\mathrm{C}$ 1s NAP-XPS ( 1 mbar CO, $2 \mathrm{mbar}_{2}$; flow mode).

out laser-induced effects). Due to technical limitations, the pressure was limited to $1 \mathrm{mbar} \mathrm{CO}$ and $2 \mathrm{mbar} \mathrm{O}_{2}$. The $\mathrm{C} 1 \mathrm{~s}$ spectra acquired during $\mathrm{CO}$ oxidation (Figure S17) detected graphitic carbon $(284.7 \mathrm{eV}),{ }^{69}$ adsorbed CO $(286.2 \mathrm{eV}),{ }^{59,70}$ a weak shoulder (around $288 \mathrm{eV}$; likely carbonate on zirconia), and gas-phase CO $(\sim 291 \mathrm{eV})$. Figure 4e,f displays the fitted peak areas vs (increasing) temperature for adsorbed $\mathrm{CO}$ and carbon. In analogy to SFG, for smoother (250 cycles) Pt films, $\mathrm{CO}$ fully disappears at a temperature $50{ }^{\circ} \mathrm{C}$ lower than for rougher (50 cycles) Pt nanoparticles (the absolute temperatures are lower due to the 10 -fold lower pressure).

However, NAP-XPS showed that much more carbon was present during the reaction on the 50 cycle (rough) $\mathrm{Pt}$ nanoparticles, which even increased during the first two temperature steps, clearly indicating $\mathrm{CO}$ disproportionation (Figure 4f). Atomic carbon apparently poisons the (lowcoordinated) active sites for oxygen activation until it is removed by oxygen at higher temperatures. This effect explains the higher reaction onset temperature of the Pt nanoparticles despite their presumably more active surface. In contrast, the smoother 250 cycle $\mathrm{Pt}$ film was much less affected by $\mathrm{C}$ poisoning, yielding a lower reaction onset temperature. After 
ignition, both $\mathrm{Pt}$ surfaces were O-covered and showed the expected hysteresis upon lowering the temperature (Figure S19). CO readsorbed at a comparably lower temperature paralleled by less coking (due to cooling in an oxygencontaining atmosphere). Throughout all experiments, the operando $\mathrm{Pt} 4 \mathrm{f}$ spectra revealed that $\mathrm{Pt}$ remained metallic (Figure S17).

In summary, combining the ALD model catalyst preparation, operando SFG/NAP-XPS/MS spectroscopy, and DFT calculations enabled us to build another bridge across the "materials and pressure gap". Few ALD Pt deposition cycles produced Pt nanoparticles with multiple inclined facets, whereas more deposition cycles $(\geq 125)$ led to more uniform Pt films. The polarization-dependent SFG revealed the molecular orientation of $\mathrm{CO}$ (relative to the macroscopic surface normal) and thus both the morphology and roughness of different ALDgrown $\mathrm{Pt}$ model catalysts. Upon $\mathrm{CO}$ adsorption at mbar pressure around $275{ }^{\circ} \mathrm{C}, \mathrm{Pt}(111)$ did not show CO disproportionation, whereas rougher $\mathrm{Pt}$ particles/films and sputtered $\mathrm{Pt}(111)$ did. According to the DFT calculations, direct $\mathrm{CO}$ dissociation is unfeasible even at stepped $\mathrm{Pt}$ surfaces. Dissociation instead occurs at high coverages via a disproportionation reaction at low-coordinated sites that structurally promote $\mathrm{CO}-\mathrm{CO}$ coupling and stabilize the remaining $\mathrm{C}$ atom. The effect of surface roughness on the $\mathrm{CO}$ oxidation was monitored at mbar pressure and elevated temperature by correlating the operando SFG and NAP-XPS spectra with the MS reactivity data. Different from the general expectation, the reaction onset temperature was higher for the smaller/rougher $\mathrm{Pt}$ nanoparticles than for the smooth $\mathrm{Pt}$ surfaces. The rougher surfaces were poisoned by carbon coking, detected by NAP-XPS, and explained by DFT calculations via $\mathrm{CO}$ disproportionation on favorable sites. Only after the removal of the carbon deposits did the rough $\mathrm{Pt}$ surfaces become active, but at $50{ }^{\circ} \mathrm{C}$ higher temperature than for smooth Pt. Upon cooldown, the smooth Pt films exhibited a wider hysteresis window and were hardly affected by $\mathrm{CO}$ disproportionation. Future studies of ALD Pt particles and films on different support materials should reveal whether reducible supports facilitate activation at lower temperature and reduce/suppress the initial carbon poisoning.

\section{ASSOCIATED CONTENT}

\section{SI Supporting Information}

The Supporting Information is available free of charge at https://pubs.acs.org/doi/10.1021/acscatal.0c03974.

Model catalysts; operando methods; measurements of CO adsorption and dissociation; DFT calculations; measurements of $\mathrm{CO}$ oxidation (PDF)

\section{AUTHOR INFORMATION}

\section{Corresponding Author}

Günther Rupprechter - Institute of Materials Chemistry, Technische Universität Wien, Vienna 1060, Austria; 이이.org/0000-0002-8040-1677;

Email: guenther.rupprechter@tuwien.ac.at

\author{
Authors \\ Verena Pramhaas - Institute of Materials Chemistry, \\ Technische Universität Wien, Vienna 1060, Austria
}

Matteo Roiaz - Institute of Materials Chemistry, Technische Universität Wien, Vienna 1060, Austria; (1) orcid.org/00000001-6896-4592

Noemi Bosio - Department of Physics and Competence Centre for Catalysis, Chalmers University of Technology, Gothenburg 41296, Sweden

Manuel Corva - Department of Physics, University of Trieste, 34127 Trieste, Italy; IOM-CNR Laboratorio TASC, 34149 Trieste, Italy

Christoph Rameshan - Institute of Materials Chemistry, Technische Universität Wien, Vienna 1060, Austria; (1) orcid.org/0000-0002-6340-4147

Erik Vesselli - Department of Physics, University of Trieste, 34127 Trieste, Italy; IOM-CNR Laboratorio TASC, 34149 Trieste, Italy; 10 orcid.org/0000-0002-6799-0032

Henrik Grönbeck - Department of Physics and Competence Centre for Catalysis, Chalmers University of Technology, Gothenburg 41296, Sweden; (1) orcid.org/0000-0002-87092889

Complete contact information is available at:

https://pubs.acs.org/10.1021/acscatal.0c03974

\section{Author Contributions}

SFG measurements were performed by V.P., M.R., M.C., and E.V. and NAP-XPS was conducted by V.P. and C.R. DFT calculations were carried out by N.B and H.G. G.R. acquired funding and coordinated the experimental work. Final interpretation and manuscript preparation were led by V.P. and G.R., with contributions from all authors.

\section{Notes}

The authors declare no competing financial interest.

\section{ACKNOWLEDGMENTS}

G.R. acknowledges funding by the Austrian Science Fund (FWF; projects DK+ Solids4Fun W1243, SFB FOXSI F4502N16 and Single Atom Catalysis I4434-N) and TU Wien (IP 2008 "SFG Spectroscopy"). H.G. acknowledges financial support from the Swedish Research Council (2016-05234). The calculations were performed at C3SE (Göteborg) through an SNIC grant. We are grateful to Ole Bethge, Emmerich Bertagnolli (ZNMS) and Stefan Löffler (USTEM) of TU Wien for the help with ALD deposition and TEM imaging, respectively. We thank MAX IV for providing beamtime (20180016) and Andrey Shavorskiy (MAX IV), Thomas Haunold, and Raffael Rameshan (both TU Wien) for the assistance.

\section{ABBREVIATIONS}

$\mathrm{ALD}$, atomic layer deposition; DFT, density functional theory; HOMO, highest occupied molecular orbital; MS, mass spectrometry; NAP-XPS, near-ambient pressure X-ray photoelectron spectroscopy; SFG, sum frequency generation; TEM, transmission electron microscopy; UHV, ultrahigh vacuum

\section{REFERENCES}

(1) Somorjai, G. A.; Li, Y., Introduction to surface chemistry and catalysis; John Wiley \& Sons: 2010.

(2) Ertl, G.; Freund, H.-J. Catalysis and Surface Science. Phys. Today 1999, 52, 32-38.

(3) Carrette, L.; Friedrich, K. A.; Stimming, U. Fuel Cells: Principles, Types, Fuels, and Applications. ChemPhysChem 2000, 1, 162-193. 
(4) Liu, K.; Wang, A.; Zhang, T. Recent Advances in Preferential Oxidation of CO Reaction over Platinum Group Metal Catalysts. ACS Catal. 2012, 2, 1165-1178.

(5) van Spronsen, M. A.; Frenken, J. W. M.; Groot, I. M. N. Surface science under reaction conditions: $\mathrm{CO}$ oxidation on Pt and Pd model catalysts. Chem. Soc. Rev. 2017, 46, 4347-4374.

(6) Liu, L.; Corma, A. Metal Catalysts for Heterogeneous Catalysis: From Single Atoms to Nanoclusters and Nanoparticles. Chem. Rev. 2018, 118, 4981-5079.

(7) Wang, A.; Li, J.; Zhang, T. Heterogeneous single-atom catalysis. Nat. Rev. Chem. 2018, 2, 65-81.

(8) Qiao, B.; Wang, A.; Yang, X.; Allard, L. F.; Jiang, Z.; Cui, Y.; Liu, J.; Li, J.; Zhang, T. Single-atom catalysis of $\mathrm{CO}$ oxidation using $\mathrm{Pt}_{1} /$ $\mathrm{FeO}_{\mathrm{x}}$. Nat. Chem. 2011, 3, 634-641.

(9) Gotterbarm, K.; Späth, F.; Bauer, U.; Bronnbauer, C.; Steinrück, H.-P.; Papp, C. Reactivity of Graphene-Supported Pt Nanocluster Arrays. ACS Catal. 2015, 5, 2397-2403.

(10) Podda, N.; Corva, M.; Mohamed, F.; Feng, Z.; Dri, C.; Dvorák, F.; Matolin, V.; Comelli, G.; Peressi, M.; Vesselli, E. Experimental and Theoretical Investigation of the Restructuring Process Induced by $\mathrm{CO}$ at Near Ambient Pressure: Pt Nanoclusters on Graphene/Ir(111). ACS Nano 2017, 11, 1041-1053.

(11) Bruix, A.; Lykhach, Y.; Matolínová, I.; Neitzel, A.; Skála, T.; Tsud, N.; Vorokhta, M.; Stetsovych, V.; Sevč́ková, K.; Mysliveček, J.; Fiala, R.; Václavå, M.; Prince, K. C.; Bruyère, S.; Potin, V.; Illas, F.; Matolín, V.; Libuda, J.; Neyman, K. M. Maximum Noble-Metal Efficiency in Catalytic Materials: Atomically Dispersed Surface Platinum. Angew. Chem., Int. Ed. 2014, 53, 10525-10530.

(12) Jones, J.; Xiong, H.; DeLaRiva, A. T.; Peterson, E. J.; Pham, H.; Challa, S. R.; Qi, G.; Oh, S.; Wiebenga, M. H.; Pereira Hernández, X. I.; Wang, Y.; Datye, A. K. Thermally stable single-atom platinum-onceria catalysts via atom trapping. Science 2016, 353, 150.

(13) Vesselli, E.; Peressi, M., Chapter 8 - Nanoscale Control of Metal Clusters on Templating Supports. In Studies in Surface Science and Catalysis., Fornasiero, P.; Cargnello, M., Eds. Elsevier: 2017; Vol. 177 , pp. $285-315$.

(14) Liu, J.; Lucci, F. R.; Yang, M.; Lee, S.; Marcinkowski, M. D.; Therrien, A. J.; Williams, C. T.; Sykes, E. C. H.; FlytzaniStephanopoulos, M. Tackling CO Poisoning with Single-Atom Alloy Catalysts. J. Am. Chem. Soc. 2016, 138, 6396-6399.

(15) Alayoglu, S.; Nilekar, A. U.; Mavrikakis, M.; Eichhorn, B. Ru-Pt core-shell nanoparticles for preferential oxidation of carbon monoxide in hydrogen. Nat. Mater. 2008, 7, 333-338.

(16) Campbell, C. T. Ultrathin metal films and particles on oxide surfaces: structural, electronic and chemisorptive properties. Surf. Sci. Rep. 1997, 27, 1-111.

(17) Vayssilov, G. N.; Lykhach, Y.; Migani, A.; Staudt, T.; Petrova, G. P.; Tsud, N.; Skála, T.; Bruix, A.; Illas, F.; Prince, K. C.; Matolín, V.; Neyman, K. M.; Libuda, J. Support nanostructure boosts oxygen transfer to catalytically active platinum nanoparticles. Nat. Mater. 2011, 10, 310-315.

(18) Suchorski, Y.; Kozlov, S. M.; Bespalov, I.; Datler, M.; Vogel, D.; Budinska, Z.; Neyman, K. M.; Rupprechter, G. The role of metal/ oxide interfaces for long-range metal particle activation during $\mathrm{CO}$ oxidation. Nat. Mater. 2018, 17, 519-522.

(19) Pacchioni, G.; Freund, H.-J. Controlling the charge state of supported nanoparticles in catalysis: lessons from model systems. Chem. Soc. Rev. 2018, 47, 8474-8502.

(20) Freund, H.-J.; Pacchioni, G. Oxide ultra-thin films on metals: new materials for the design of supported metal catalysts. Chem. Soc. Rev. 2008, 37, 2224-2242.

(21) An, K.; Alayoglu, S.; Musselwhite, N.; Plamthottam, S.; Melaet, G.; Lindeman, A. E.; Somorjai, G. A. Enhanced CO Oxidation Rates at the Interface of Mesoporous Oxides and Pt Nanoparticles. J. Am. Chem. Soc. 2013, 135, 16689-16696.

(22) Somorjai, G. A. Surface science at high pressures. Z. Phys. Chem. 1996, 197, 1-19.

(23) Baldelli, S.; Eppler, A. S.; Anderson, E.; Shen, Y. R.; Somorjai, G. A. Surface enhanced sum frequency generation of carbon monoxide adsorbed on platinum nanoparticle arrays. J. Chem. Phys. 2000, 113, 5432-5438.

(24) Rupprechter, G.; Dellwig, T.; Unterhalt, H.; Freund, H.-J. CO adsorption on $\mathrm{Ni}(100)$ and $\mathrm{Pt}(111)$ studied by infrared-visible sum frequency generation spectroscopy: design and application of an SFGcompatible UHV-high-pressure reaction cell | SpringerLink. Top. Catal. 2001, 15, 19-26.

(25) Freund, H.-J.; Bäumer, M.; Libuda, J.; Risse, T.; Rupprechter, G.; Shaikhutdinov, S. Preparation and characterization of model catalysts: from ultrahigh vacuum to in situ conditions at the atomic dimension. J. Catal. 2003, 216, 223-235.

(26) Rupprechter, G. Sum Frequency Laser Spectroscopy during Chemical Reactions on Surfaces. MRS Bull. 2007, 32, 1031-1037.

(27) Rupprechter, G., Sum Frequency Generation and PolarizationModulation Infrared Reflection Absorption Spectroscopy of Functioning Model Catalysts from Ultrahigh Vacuum to Ambient Pressure. In Adv. Catal., Gates, B. C.; Knözinger, H., Eds. Academic Press: 2007; Vol. 51, pp. 133-263.

(28) Somorjai, G. A.; York, R. L.; Butcher, D.; Park, J. Y. The evolution of model catalytic systems; studies of structure, bonding and dynamics from single crystal metal surfaces to nanoparticles, and from low pressure $\left(<10^{-3}\right.$ Torr $)$ to high pressure $\left(>10^{-3}\right.$ Torr $)$ to liquid interfaces. Phys. Chem. Chem. Phys. 2007, 9, 3500-3513.

(29) Salmeron, M.; Schlögl, R. Ambient pressure photoelectron spectroscopy: A new tool for surface science and nanotechnology. Surf. Sci. Rep. 2008, 63, 169-199.

(30) Rupprechter, G.; Weilach, C. Spectroscopic studies of surfacegas interactions and catalyst restructuring at ambient pressure: mind the gap! J. Phys.: Condens. Matter 2008, 20, 184019.

(31) Gao, F.; Wang, Y.; Cai, Y.; Goodman, D. W. CO Oxidation on Pt-Group Metals from Ultrahigh Vacuum to Near Atmospheric Pressures. 2. Palladium and Platinum. J. Phys. Chem. C 2009, 113, 174-181.

(32) Jiang, T.; Mowbray, D. J.; Dobrin, S.; Falsig, H.; Hvolbæk, B.; Bligaard, T.; Nørskov, J. K. Trends in CO Oxidation Rates for Metal Nanoparticles and Close-Packed, Stepped, and Kinked Surfaces. J. Phys. Chem. C 2009, 113, 10548-10553.

(33) Sauer, J.; Freund, H.-J. Models in Catalysis. Catal. Lett. 2015, 145, 109-125.

(34) Anic, K.; Wolfbeisser, A.; Li, H.; Rameshan, C.; Föttinger, K.; Bernardi, J.; Rupprechter, G. Surface Spectroscopy on UHV-Grown and Technological $\mathrm{Ni}-\mathrm{ZrO}_{2}$ Reforming Catalysts: From UHV to Operando Conditions. Top. Catal. 2016, 59, 1614-1627.

(35) Hayek, K.; Fuchs, M.; Klötzer, B.; Reichl, W.; Rupprechter, G. Studies of metal-support interactions with "real" and "inverted" model systems: reactions of $\mathrm{CO}$ and small hydrocarbons with hydrogen on noble metals in contact with oxides. Top. Catal. 2000, $13,55-66$.

(36) Palomino, R. M.; Gutiérrez, R. A.; Liu, Z.; Tenney, S.; Grinter, D. C.; Crumlin, E.; Waluyo, I.; Ramírez, P. J.; Rodriguez, J. A.; Senanayake, S. D. Inverse Catalysts for $\mathrm{CO}$ Oxidation: Enhanced Oxide-Metal Interactions in $\mathrm{MgO} / \mathrm{Au}(111), \mathrm{CeO}_{2} / \mathrm{Au}(111)$, and $\mathrm{TiO}_{2} / \mathrm{Au}(111)$. ACS Sustainable Chem. Eng. 2017, 5, 10783-10791.

(37) Rameshan, C.; Li, H.; Anic, K.; Roiaz, M.; Pramhaas, V.; Rameshan, R.; Blume, R.; Hävecker, M.; Knudsen, J.; Knop-Gericke, A.; Rupprechter, G. In situ NAP-XPS spectroscopy during methane dry reforming on $\mathrm{ZrO}_{2} / \mathrm{Pt}\left(\begin{array}{lll}1 & 1 & 1\end{array}\right)$ inverse model catalyst. J. Phys.: Condens. Matter 2018, 30, 264007.

(38) Ritala, M.; Niinistö, J. Industrial Applications of Atomic Layer Deposition. ECS Trans. 2009, 25, 641-652.

(39) Kääriäinen, T.; Cameron, D.; Kääriäinen, M. L.; Sherman, A., ALD Applications and Industry. In Atomic Layer Deposition: Principles, Characteristics, and Nanotechnology Applications, Second Edition, Scrivener Publishing LLC: 2013; pp. 215-242.

(40) Lu, J.; Elam, J. W.; Stair, P. C. Atomic layer depositionSequential self-limiting surface reactions for advanced catalyst "bottom-up" synthesis. Surf. Sci. Rep. 2016, 71, 410-472. 
(41) Lee, H.-B.-R.; Mullings, M. N.; Jiang, X.; Clemens, B. M.; Bent, S. F. Nucleation-Controlled Growth of Nanoparticles by Atomic Layer Deposition. Chem. Mater. 2012, 24, 4051-4059.

(42) ALD NanoSolutions. https://www.aldnanosolutions.com/.

(43) Ding, K.; Gulec, A.; Johnson, A. M.; Schweitzer, N. M.; Stucky, G. D.; Marks, L. D.; Stair, P. C. Identification of active sites in CO oxidation and water-gas shift over supported Pt catalysts. Science 2015, 350, 189.

(44) Wang, H.-F.; Gan, W.; Lu, R.; Rao, Y.; Wu, B.-H. Quantitative spectral and orientational analysis in surface sum frequency generation vibrational spectroscopy (SFG-VS). Int. Rev. Phys. Chem. 2005, 24, 191-256.

(45) Lu, R.; Gan, W.; Wu, B.-H.; Chen, H.; Wang, H.-F. Vibrational Polarization Spectroscopy of $\mathrm{CH}$ Stretching Modes of the Methylene Group at the Vapor/Liquid Interfaces with Sum Frequency Generation. J. Phys. Chem. B 2004, 108, 7297-7306.

(46) Galletto, P.; Unterhalt, H.; Rupprechter, G. The molecular orientation of $\mathrm{CO}$ on $\mathrm{Pd}(111)$ : a polarization-dependent SFG study. Chem. Phys. Lett. 2003, 367, 785-790.

(47) Li, X.; Roiaz, M.; Pramhaas, V.; Rameshan, C.; Rupprechter, G. Polarization-Dependent SFG Spectroscopy of Near Ambient Pressure CO Adsorption on $\mathrm{Pt}(111)$ and $\mathrm{Pd}(111)$ Revisited. Top. Catal. 2018, $61,751-762$.

(48) Xu, J.; Yates, J. T., Jr. Terrace width effect on adsorbate vibrations- A comparison of $\mathrm{Pt}(335)$ and $\mathrm{Pt}(112)$ for chemisorption of CO. Surf. Sci. 1995, 327, 193-201.

(49) Tüshaus, M.; Schweizer, E.; Hollins, P.; Bradshaw, A. M. Yet another vibratlonal study of the adsorption system $\mathrm{Pt}\{111\}$-CO. J. Electron Spectrosc. Relat. Phenom. 1987, 44, 305-316.

(50) Shen, Y. R. Surface properties probed by second-harmonic and sum-frequency generation. Nature 1989, 337, 519-525.

(51) Morkel, M.; Unterhalt, H.; Klüner, T.; Rupprechter, G.; Freund, H.-J. Interpreting intensities in vibrational sum frequency generation (SFG) spectroscopy: CO adsorption on Pd surfaces. Surf. Sci. 2005, 586, 146-156.

(52) Höbel, F.; Bandara, A.; Rupprechter, G.; Freund, H.-J. Deactivation of $\mathrm{Pd}$ particles supported on $\mathrm{Nb}_{2} \mathrm{O}_{5} / \mathrm{Cu}_{3} \mathrm{Au}(100)$ : SFG and TPD studies from UHV to $100 \mathrm{mbar}$. Surf. Sci. 2006, 600, 963-970.

(53) Rupprechter, G.; Dellwig, T.; Unterhalt, H.; Freund, H.-J. High-Pressure Carbon Monoxide Adsorption on $\mathrm{Pt}(111)$ Revisited: A Sum Frequency Generation Study. J. Phys. Chem. B 2001, 105, 37973802.

(54) Hayden, B. E.; Kretzschmar, K.; Bradshaw, A. M.; Greenler, R. G. An infrared study of the adsorption of $\mathrm{CO}$ on a stepped platinum surface. Surf. Sci. 1985, 149, 394-406.

(55) Backus, E. H. G.; Bonn, M. A quantitative comparison between reflection absorption infrared and sum-frequency generation spectroscopy. Chem. Phys. Lett. 2005, 412, 152-157.

(56) Klünker, C.; Balden, M.; Lehwald, S.; Daum, W. CO stretching vibrations on $\mathrm{Pt}(111)$ and $\mathrm{Pt}(110)$ studied by sum frequency generation. Surf. Sci. 1996, 360, 104-111.

(57) Härle, H.; Mendel, K.; Metka, U.; Volpp, H. R.; Willms, L.; Wolfrum, J. Temperature dependence $(90-440 \mathrm{~K})$ of the vibrational spectra of $\mathrm{CO}$ adsorbed on platinum(111) studied by sum-frequency generation. Chem. Phys. Lett. 1997, 279, 275-281.

(58) Jørgensen, M.; Grönbeck, H. Scaling Relations and Kinetic Monte Carlo Simulations To Bridge the Materials Gap in Heterogeneous Catalysis. ACS Catal. 2017, 7, 5054-5061.

(59) Tränkenschuh, B.; Fritsche, N.; Fuhrmann, T.; Papp, C.; Zhu, J. F.; Denecke, R.; Steinrück, H.-P. A site-selective in situ study of CO adsorption and desorption on $\mathrm{Pt}(355)$. J. Chem. Phys. 2006, 124, No. 074712.

(60) McCrea, K.; Parker, J. S.; Chen, P.; Somorjai, G. Surface structure sensitivity of high-pressure $\mathrm{CO}$ dissociation on $\mathrm{Pt}(557)$, $\mathrm{Pt}(100)$ and $\mathrm{Pt}(111)$ using sum frequency generation surface vibrational spectroscopy. Surf. Sci. 2001, 494, 238-250.

(61) Vandichel, M.; Grönbeck, H. A dimer path for CO dissociation on PtSn. Catal. Sci. Technol. 2019, 9, 695-701.
(62) Olmos-Asar, J. A.; Monachino, E.; Dri, C.; Peronio, A.; Africh, C.; Lacovig, P.; Comelli, G.; Baldereschi, A.; Peressi, M.; Vesselli, E. $\mathrm{CO}$ on Supported $\mathrm{Cu}$ Nanoclusters: Coverage and Finite Size Contributions to the Formation of Carbide via the Boudouard Process. ACS Catal. 2015, 5, 2719-2726.

(63) Ng, M. L.; Abild-Pedersen, F.; Kaya, S.; Mbuga, F.; Ogasawara, H.; Nilsson, A. Low Barrier Carbon Induced CO Dissociation on Stepped Cu. Phys. Rev. Lett. 2015, 114, 246101.

(64) Trinchero, A.; Hellman, A.; Grönbeck, H. Methane oxidation over Pd and Pt studied by DFT and kinetic modeling. Surf. Sci. 2013, 616, 206-213.

(65) Deutschmann, O.; Schmidt, R.; Behrendt, F.; Warnat, J. Numerical modeling of catalytic ignition. ymp. (Int.) Combust. 1996, 26, 1747-1754.

(66) Vogel, D.; Spiel, C.; Suchorski, Y.; Trinchero, A.; Schlögl, R.; Grönbeck, H.; Rupprechter, G. Local Catalytic Ignition during CO Oxidation on Low-Index Pt and Pd Surfaces: A Combined PEEM, MS, and DFT Study. Angew. Chem., Int. Ed. 2012, 51, 10041-10044.

(67) Perez-Alonso, F. J.; McCarthy, D. N.; Nierhoff, A.; HernandezFernandez, P.; Strebel, C.; Stephens, I. E. L.; Nielsen, J. H.; Chorkendorff, I. The Effect of Size on the Oxygen Electroreduction Activity of Mass-Selected Platinum Nanoparticles. Angew. Chem., Int. Ed. 2012, 51, 4641-4643.

(68) Jørgensen, M.; Grönbeck, H. The Site-Assembly Determines Catalytic Activity of Nanoparticles. Angew. Chem., Int. Ed. 2018, 57, 5086-5089.

(69) Pazhetnov, E. M.; Koshcheev, S. V.; Boronin, A. I. Formation Mechanism and Structure of Monatomic Carbon Films in Ethylene Decomposition on the $\mathrm{Pt}(111)$ Surface According to XPS Data. Kinet. Catal. 2003, 44, 414-419.

(70) Toyoshima, R.; Yoshida, M.; Monya, Y.; Suzuki, K.; Amemiya, K.; Mase, K.; Mun, B. S.; Kondoh, H. A high-pressure-induced dense $\mathrm{CO}$ overlayer on a $\mathrm{Pt}(111)$ surface: a chemical analysis using in situ near ambient pressure XPS. Phys. Chem. Chem. Phys. 2014, 16, 23564-23567. 